\title{
The Quest for Quality Electrocardiographic Recording
}

Javier Carcía-Niebla. ${ }^{1}$

For correct electrocardiography (ECG) diagnosis and interpretation, it is important not only to distinguish normal from pathological electrocardiograms, but also to ensure that they have been properly recorded.

Heden et al.,' reported that $2 \%$ of the 11,000 ECGs analyzed showed interchanged electrode placement. Thus, if $300 \mathrm{mi}$ Ilion ECGs are performed annually in the world, 6 million are erroneously recorded. This figure could even triple if one includes other frequent mistakes, such as vertical displacement of precordial electrodes and the distal placement of these on the limbs instead of the trunk. ${ }^{2}$ Few manuals on electrocardiography have devoted space to warn about the effects of ECG recordings that do not conform to standards, but it seems that this is changing. ${ }^{3}$

This issue of the Journal contains two interesting articles by Rosen et al., who form part of the research group led by Dr. Adrian Baranchuk, which address the most common mistakes made in daily practice in relation to improper placement of limb and precordial electrodes, as well as tell-tale signs for their detection. ${ }^{4.5}$

About the Author: Javier García Niebla is a registered nurse with a degree in Nursing from the University of La Laguna and an associate lecturer at the University School of Nursing, Hospital "Ntra. Sra. de La Candelaria". For almost six years he directed the webpage of the Spanish Association of Nursing in Cardiology. As an investigator and author, he has published in dozens of scientific journals in the field of cardiology and is a recognized expert in electrocardiography, and a regular collaborator of Prof. Antoni Bayés de Luna.
In this editorial we will elaborate on certain issues directly related to possible errors on performing an ECG.

\section{Is it important to prepare the patient for an ECG?}

Yes. Patients must be informed of the procedure to be performed, emphasizing that it is painless and harmless but they must lie still, breathe normally and refrain from talking. Nervousness and sweating are to be resolved before starting the procedure. Proper skin preparation, with shaving if necessary, is required to reduce impedance and ensure adhesion of the electrode. This greatly helps to minimize the appearance of artifacts that can sometimes cause significant diagnostic errors. ${ }^{6}$

Is it easy to identify ECG patterns obtained with reversal of limb electrodes?

Yes. They are generally easy to identify. Only one pattern, resulting from the reversal of left arm and left leg electrodes, may be easily overlooked, even by experts. The presence of a P wave in lead I with greater amplitude than that in lead II and a positive terminal P wave morphology $(-/+)$ in lead III can sometimes alert us to this error.? Given the low specificity of these criteria, it is advisable to check for this error and repeat the ECG to ensure correct electrode placement.

\section{Can limb electrodes be placed on the trunk?}

No. Proximal placement of limb electrodes or their placement on the trunk is not compatible with a standard ECG. ${ }^{8}$ The advent of easily applicable adhesive electrodes with decreased muscle noise has favored this practice (Figure 1). ${ }^{9}$ ECG changes are clearly visible when limb electrodes are placed on the trunk. In these cases, there is a QRS axis deviation to the right, which decreases the voltage of the $R$ wave in leads I and aVL and increases it in leads II, III, and aVF. In a patient with necrotic $Q$ wave in leads II, III and aVF, placing limb electrodes on the trunk may reduce both the voltage and the duration of the

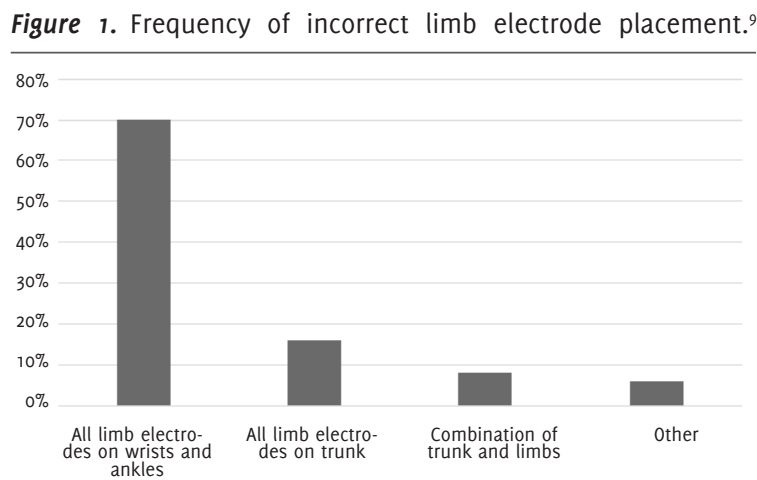

Figure 2. Proportion of professionals who correctly positioned the $V_{1}$ electrode (adapted from Rajaganeshan et al.). ${ }^{14}$

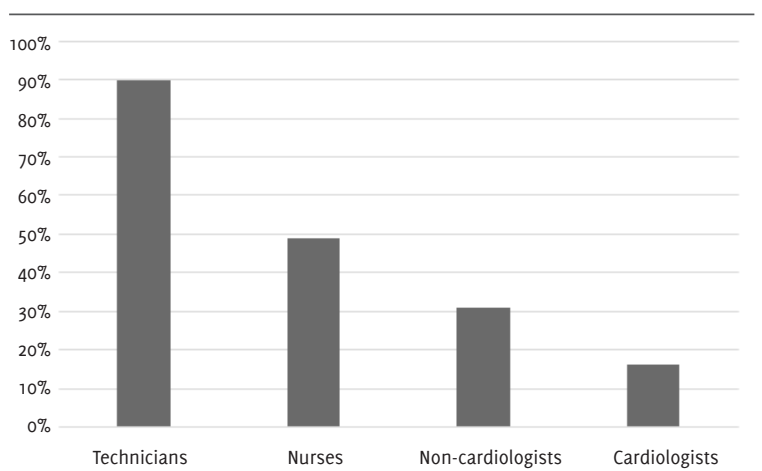

${ }^{1}$ Servicios Sanitarios del Área de Salud de El Hierro, Valle del Golfo Health Center. Ex-member of the Board of Directors, Spanish Association of Nursing in Cardiology. Collaborating lecturer of the University School of Nursing. University Hospital La. Candelaria, Spain. 
Figure 3. The $P$ wave is positive in $V_{1}-V_{2}$ (arrows) when the electrodes are correctly placed ( $A$ ) on the 4 th intercostal space (ICS). When $\mathrm{V}_{1}-\mathrm{V}_{2}$ electrodes are misplaced on the 3rd ICS (B), the low-voltage or flattened $P$ wave in $V_{2}$ (arrow) is the tell-tale sign of high placement. And when the $V_{1}-V_{2}$ electrodes are misplaced on the

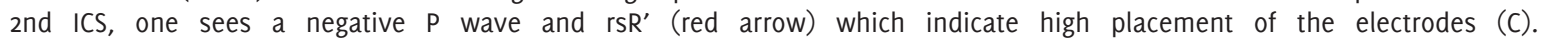

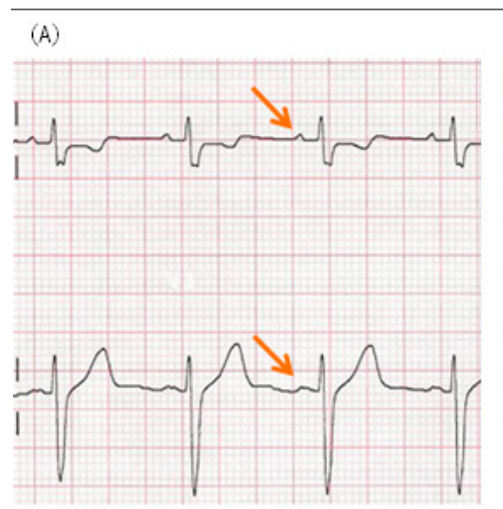

4th ICS

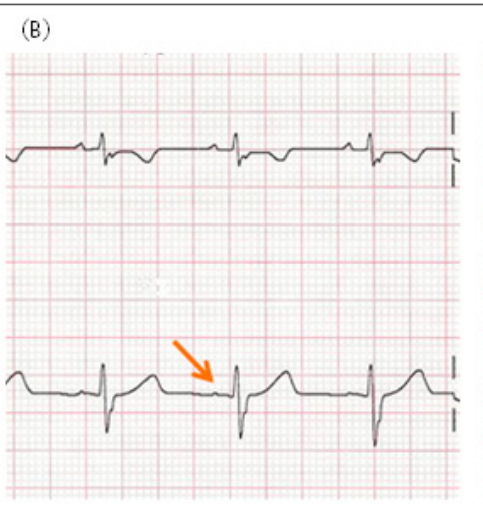

3rd ICS

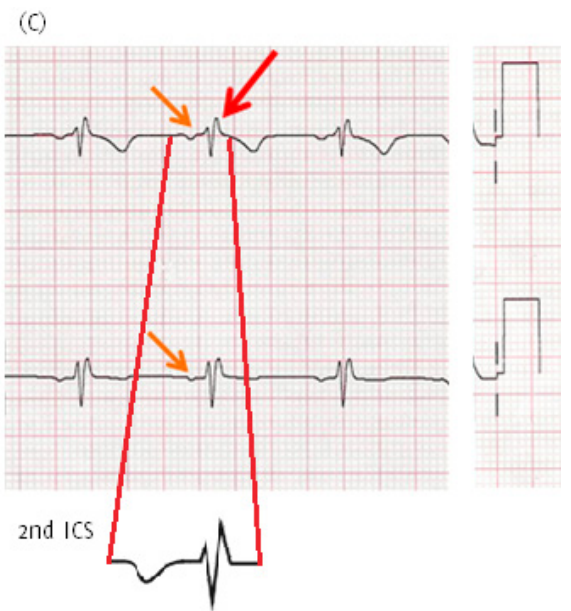

Figure 4. Effect of a high-pass filter in lead $\mathrm{V}_{4}$. Note how the voltages of the $\mathrm{R}$ wave (14.84 $\mathrm{mm}$ to 12.82 $\mathrm{mm})$ and the $\mathrm{S}$ wave $(6.68 \mathrm{~mm}$ to $2.52 \mathrm{~mm})$ are reduced when applying a non-standard $25 \mathrm{~Hz}$ filter.

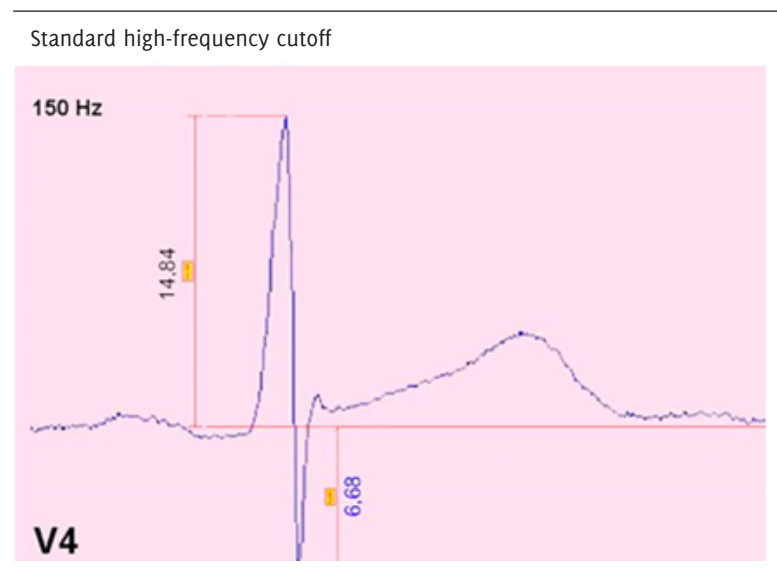

wave. If for any reason we need to perform the ECG with this non-standard placement (a patient with Parkinson's, for example), this should be expressly recorded in writing and taken into account in the interpretation.

\section{Is it necessary to place the precordial electrodes exactly on their established sites?}

Yes, precordial lead electrodes must be placed exactly on their specific internationally established anatomical locations. ${ }^{10} \mathrm{Se}-$ veral published studies have described the ECG changes that occur when the electrodes are misplaced..$^{11,12}$

Do professionals who regularly perform ECG demonstrate better electrode placement?

No. Even technicians with an average of 15 years or more experience and who perform over 30 ECGs a day can make important mistakes." However, their theoretical knowledge about precordial lead placement is superior to that of other professionals (Figure 2). ${ }^{13}$ The most common mistakes include:

A) High placement of $\mathrm{V}_{1}-\mathrm{V}_{2}$.

B) $V_{5}$-V6 placed too low in some cases or located along the curvature of the 5 th intercostal space.

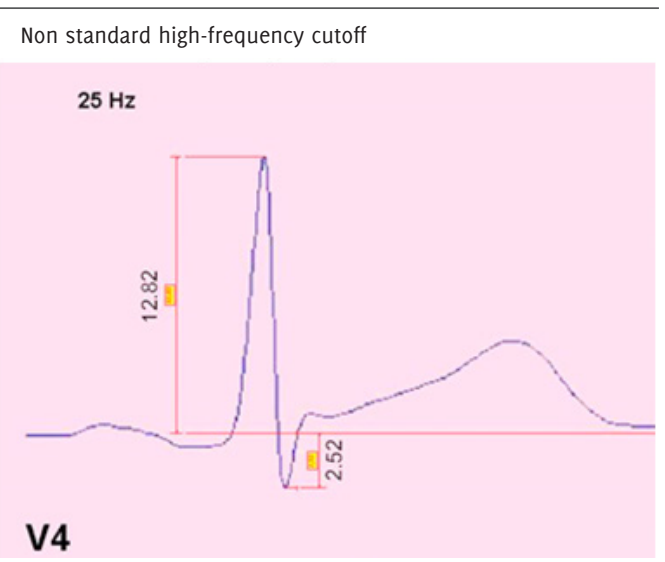

Once the ECG has been obtained, what are the tell-tale signs of high $V_{1}-V_{2}$ placement?

Three morphologies help identify high placement of these electrodes (Figure 3) ) $^{14,15}$ :

a) a negative $P$ wave in $V_{1}$ only. Under normal conditions, the $\mathrm{P}$ wave in $\mathrm{V}_{1}$ is positive or biphasic $+/-$, more positive than negative with a mild slope.

b) The rSr' morphology with a negative $\mathrm{P}$ wave is exclusive to ECGs recorded with high placement of the $\mathrm{V}_{1}$ electrode on the 2nd intercostal space. It is seen in $17 \%$ of cases of inappropriate placement in healthy individuals.

c) A negative component of the $P$ wave or a flattened $P$ wave in $V_{2}$ are indicators of high placement.

High positioning of the electrodes $\mathrm{V}_{1}-\mathrm{V}_{2}$ can mimic a Brugada type 2 pattern. However the $r^{`}$ in this case is narrow with the base of the lower triangle measuring less than $4 \mathrm{~mm} .{ }^{16,17}$

\section{Can ECG filter settings affect the ECG?}

Yes. When filters are applied to prevent unwanted noise and obtain better quality recording of the cardiac signal, the ECC can sometimes be markedly affected unless the recommended cutoffs are applied: 


\section{Muscle noise filter}

If the cutoff is too low, signals which are important from the clinical point of view can be eliminated (pacemaker spikes, amplitude of the R wave, QRS notches, etc.) (Figure 4). ${ }^{18}$ The cutoff frequency should be at least $150 \mathrm{~Hz}$ in the case of adults and adolescents and up to $250 \mathrm{~Hz}$ in the case of children.

\section{Baseline filter}

It is important to remove the noise generated by a wandering baseline which may occur as a result of small movements and breathing of the patient. Inadequate filter application can result in significant distortion of the ST segment and T wave, simulating acute coronary syndrome or Brugada syndrome. ${ }^{19}$ The recommended cutoff is $0.05 \mathrm{~Hz}$, increasing up to $0.67 \mathrm{~Hz}$ if linear filters with zero phase distortion are used.

\section{How can we reduce the number of errors?}

In view of the above considerations, it is necessary to promote specific training programs and refresher courses on the performance and interpretation of ECGs, based on the latest recommendations made by the major international scientific societies. These should include the correct placement of the electrodes, assimilating the significance of correct technique, the reading of normal and pathological patterns, together with a specific focus on recognizing ECG patterns resulting from improper positioning of electrodes, the identification of artifacts and other technical problems that could lead to misinterpretation.

\section{References}

1. Heden B, Ohlsson M, Edenbrandt L, Rittner R, Pahlm 0, Peterson C. Artificial neural networks for recognition of electrocardiographic lead reversal. Am J Cardiol. 1995 May 1;75(14):929-33.

2. García-Niebla J, Llontop-García P, Valle-Racero JI, Serra-Autonell G, Batchvarov VN, de Luna $A B$. Technical mistakes during the acquisition of the electrocardiogram. Ann Noninvasive Electrocardiol. 2009 0ct;14(4):389-403.

3. Bayés de Luna A. Clinical electrocardiography: a textbook. 4th ed. Chichester, West Sussex, UK: Wiley-Blackwell; c2012.

4. Rosen A, Koppikar S, Shaw C, Baranchuk A. Common ECG lead placement errors. Part I: Limb lead reversals. Int J Med Students. 2014 Jul-0ct;2(3):92-8. 5. Rosen A, Koppikar S, Shaw C, Baranchuk A. Common ECG lead placement errors. Part II: Precordial Misplacements. Int J Med Students. 2014 Jul$0 c t ; 2(3): 99-103$.
6. Barake W, Baranchuk A, Pinter A. Pseudo-ventricular tachycardia mimicking malignant arrhythmia in a patient with rapid atrial fibrillation. Am J Crit Care. 2014 May;23(3):270-2.

7. Abdollah H, Milliken JA. Recognition of electrocardiographic left-arm/leftleg lead-reversal. Am J Cardiol. 1997 Nov 1;80(9):1247-9.

8. Pahlm 0, Haisty WK Jr, Edenbrandt L, Wagner NB, Sevilla DC, Selvester RH, et al. Evaluation of changes in standard electrocardiographic QRS waveforms recorded from activity-compatible proximal limb lead positions. Am J Cardiol. $1992 \operatorname{Jan} 15 ; 69(3): 253-7$.

9. Turner AM, 12 Lead recordings: Implications of an inconsistent approach. Cardiology News 2006; 9: 10-12.

10. Kligfield P, Gettes LS, Bailey JJ, Childers R, Deal BJ, Hancock EW, et al. Recommendations for the standardization and interpretation of the electrocardiogram: part I: The electrocardiogram and its technology: a scientific statement from the American Heart Association Electrocardiography and Arrhythmias Committee, Council on Clinical Cardiology; the American College of Cardiology Foundation; and the Heart Rhythm Society: endorsed by the International Society for Computerized Electrocardiology. Circulation. 2007 Mar 13;115(10):1306-24.

11. Garcia-Niebla J. Comparison of $\mathrm{p}$-wave patterns derived from correct and incorrect placement of $\mathrm{V}_{1}-\mathrm{V}_{2}$ electrodes. J Cardiovasc Nurs. 2009 MarApr;24(2):156-61.

12. Zema M], Kligfield P. ECG poor R-wave progression: review and synthesis. Arch Intern Med. 1982 Jun;142(6):1145-8.

13. Wenger W, Kligfield P. Variability of precordial electrode placement during routine electrocardiography. J Electrocardiol. 1996 Jul;29(3):179-84.

14. Rajaganeshan R, Ludlam CL, Francis DP, Parasramka SV, Sutton R. Accuracy in ECG lead placement among technicians, nurses, general physicians and cardiologists. Int J Clin Pract. 2008 Jan;62(1):65-70.

15. Garcia-Niebla J, Rodriguez-Morales $M$, Valle-Racero Jl, de Luna AB. Negative $\mathrm{P}$ wave in $\mathrm{V}_{1}$ is the key to identifying high placement of $\mathrm{V}_{1}-\mathrm{V}_{2}$ electrodes in nonpathological subjects. Am J Med. 2012 Sep;125(9):e9-10.

16. García-Niebla J, Baranchuk A, de Luna AB. True Brugada pattern or only high V1-V2 electrode placement? J Electrocardiol. 2014 Sep-0ct;47(5):756-8

17. Baranchuk A, Enriquez A, García-Niebla J, Bayés-Cenís A, Villuendas R, Bayés de Luna A. Differential diagnosis of ' $S^{\prime} r^{\prime}$ pattern in leads $V_{1}-V_{2}$. Comprehensive review and proposed algorithm. Ann Noninv Electrocardiol. 2014: Forthcoming.

18. Garcia-Niebla J, Serra-Autonell C. Effects of inadequate low-pass filter application. J Electrocardiol. 2009 Jul-Aug;42(4):303-4.

19. Garcia-Niebla J, Serra-Autonell G, Bayes de Luna A. Brugada syndrome electrocardiographic pattern as a result of improper application of a high pass filter. Am J Cardiol. 2012 Jul 15;110(2):318-20.

\section{Acknowledgments}

None.

Conflict of Interest Statement at Funding

The Author has no funding, financial relationships or conflicts of interest to disclose.

Cite as:

García-Niebla J. The Quest for Quality Electrocardiographic Recording. Int J Med Students. 2014 Jul-0ct;2(3):87-9. 